\title{
Millimole per Liter per Gram
}

National Cancer Institute

\section{Source}

National Cancer Institute. Millimole per Liter per Gram. NCI Thesaurus. Code C119423.

A unit of concentration equal to millimoles per liter, divided by grams. 